Revista lus et Praxis, Año 23, No 2, 2017, pp. 121 - 146

ISSN 0717 - 2877

Universidad de Talca - Facultad de Ciencias Jurídicas y Sociales

Daños por infracción del deber matrimonial de fidelidad.

Una cuestión nuclear en el debate sobre la responsabilidad civil en la familia

Hernán Corral Talciani

Trabajo recibido el 13 de julio de 2016 y aprobado el 18 de agosto de 2016

\title{
Daños por infracción del deber matrimonial de fidelidad. Una cuestión nuclear en el debate sobre la responsabilidad civil en la familia
}

\author{
At the Heart of the Debate over Civil Liability in Family Law: An \\ Award of Damages for the Breach of Duty to Matrimonial Fidelity
}

\author{
Hernán Corral TalCiani*
}

\begin{abstract}
Resumen
En los últimos años ha crecido en Chile el interés por la aplicación de la responsabilidad civil en las relaciones de familia, y en particular en las originadas por el matrimonio. Existe consenso en que ella procede cuando se lesionan derechos o intereses cuyo daño se indemnizaría incluso si no hubiera matrimonio entre el autor y la víctima. La polémica se concentra, en consecuencia, en la lesión de derechos o intereses que derivan del propio estatuto matrimonial. El presente trabajo pretende focalizar el análisis en el incumplimiento de uno de los principales deberes del matrimonio: el de guardarse fe. Se postula que la responsabilidad civil puede tener lugar en cuanto instrumento reparatorio si se verifican sus requisitos propios, siempre que el incumplimiento sea serio, doloso y genere daños que superen el umbral de tolerancia de las relaciones en familia. Finalmente, se sostiene que la tesis de que solo habría responsabilidad civil cuando se lesionan derechos fundamentales del cónyuge inocente es más retórica que práctica si se piensa que el daño moral por infidelidad siempre podrá concebirse como lesión de los derechos a la integridad psíquica o a la honra.
\end{abstract}

ABSTRACT

In the recent years, the interest on the application of civil liability within family relationships has grown, in particular, to those derived from marriage. There is consensus that it could proceed in the cases when damages would be compensated even if there were no marriage whatsoever between the offender and the victim. The controversy focuses, therefore, in the infringement of the rights or interests deriving from the same legal statute of marriage. This paper intends to focus on the analysis of the breach of one of the main duties of marriage: reciprocal duty to fidelity. We affirm that civil liability can take place as a reparative instrument if its own requirements are verified, provided that the breach is serious, and generate malicious damage exceeding the threshold of tolerance of family relations. Finally, it is argued that the thesis that affirms that liability would only proceed when fundamental rights of the innocent spouse are injured is more rhetorical than practical, especially if the non-pecuniary loss of infidelity can always be conceived as an injury to the constitutional rights to mental integrity or honor.

\footnotetext{
* Doctor en Derecho por la Universidad de Navarra. Profesor de Derecho Civil en la Universidad de los Andes (Santiago de Chile). Correo electrónico: hcorral@uandes.cl.
} 
Palabras Clave

Responsabilidad civil, matrimonio, deber de fidelidad

KEY WORDS

Civil liability, mariage, duty to fidelity

\section{Consideraciones preliminares}

\section{El núcleo del debate sobre responsabilidad civil en el matrimonio}

En el estado actual de la reciente discusión sobre la responsabilidad civil por daños en el matrimonio, parece haberse arribado a un cierto consenso en que el vínculo matrimonial no puede establecer un estatuto de inmunidad frente a la responsabilidad civil cuando se trata de daños que se indemnizarían incluso si no hubiera matrimonio entre el hechor y la víctima. Por ejemplo, si se trata de muerte, lesiones o maltrato físico y psíquico, contagio de enfermedades de transmisión sexual o daños a derechos fundamentales como la honra, la imagen o la intimidad. Los autores que se muestran reacios o directamente contrarios a considerar aplicable la responsabilidad civil al incumplimiento de deberes conyugales así lo afirman ${ }^{1}$. Tampoco parece haber discrepancias en la procedencia de la responsabilidad civil entre cónyuges en materias patrimoniales ${ }^{2}$.

La controversia subsiste, en cambio, sobre si procede o no la responsabilidad civil entre cónyuges tratándose de materias no patrimoniales y en las que la ilicitud no proviene de un delito o cuasidelito penal o del principio de no dañar a otro (neminem laedere), sino de la infracción del estatuto matrimonial que los liga. El problema real entonces, y en el que deben centrarse los esfuerzos dogmáticos, se podría presentar de esta manera: si eliminamos hipotéticamente el vínculo matrimonial entre el ofensor y la víctima, ¿desaparece o se mantiene la posibilidad de accionar a título de responsabilidad civil? Si se afirma que desaparece, se estará asumiendo una posición contraria a la aplicación de la responsabilidad civil por incumplimiento de deberes matrimoniales; si se mantiene, aunque sea con matices, se estará a favor de la aplicabilidad de dicha responsabilidad en caso de infracción dañosa de dichos deberes.

\footnotetext{
1 Severin (2011a), pp. 164-206; Tapia (2015), pp. 233-234; Barcia (2011), p. 98; Kemelmajer (2015), pp. 198-201. BARCIA y RiverA (2015), pp. 41 y ss. sostienen que la responsabilidad civil se generaría solo cuando el incumplimiento del deber conyugal constituya un ilícito agravado, lo que se daría en la medida en que se viole otro estatuto jurídico diverso del matrimonial: ley penal, derechos fundamentales, regulación laboral y otras similares.

${ }^{2}$ En ello incide que el Código Civil reconozca expresamente la procedencia de indemnización en estos casos, como sucede con los arts. 1768, 1771 y 2483.
} 
El prototipo de deber matrimonial que solo se puede violar mediante conductas que no constituyen otro tipo de ilícitos es el deber de guardarse fe o de fidelidad, establecido en los arts. 131 y 132 del Código Civil. Si no existe matrimonio entre dos personas no puede haber incumplimiento del deber de fidelidad y, por tanto, aunque una de ellas sufra por las relaciones sentimentales que entable con un tercero, no habrá hecho ilícito que justifique una demanda de indemnización de perjuicios. Si hay matrimonio, el hecho ilícito aparece: se incumple un deber marital, y en tal caso la pregunta sobre la posibilidad de obtener reparación del daño causado por la vía civil se vuelve pertinente.

Antes de proseguir, sin embargo, nos parece necesario hacer frente a algunos argumentos que postulan la absoluta incompatibilidad del Derecho de Familia con el régimen jurídico de la responsabilidad civil, ya que de aceptarse esta posición la respuesta negativa a la pregunta que se ha formulado se impondría por principio.

\section{Derecho de Familia y Derecho de la Responsabilidad Civil: ¿incompatibilidad o complementariedad?}

A favor de la incompatibilidad se sostiene que el Derecho de Familia, y dentro de él el Derecho matrimonial, es un derecho especialísimo, en que se regulan conductas y afectos, que escapan del plano patrimonial o económico, por lo que por su misma naturaleza se resiste a que se apliquen las reglas de la responsabilidad civil.

Los argumentos teórico-conceptuales que suelen aducirse para defender esta posición podrían resumirse así:

$\left.1^{\circ}\right)$ El Derecho matrimonial tiene sus propias sanciones al incumplimiento de los deberes conyugales, lo que revela que el legislador no ha querido que el cónyuge ofendido pueda pedir indemnización de perjuicios en contra del otro, lo cual es congruente con la idea de intervención mínima del Estado propia de las sociedades posmodernas ${ }^{3}$.

$2^{\circ}$ ) Los deberes matrimoniales son esencialmente éticos, de modo que su transgresión no genera todas las consecuencias que se darían si se tratara de genuinos deberes jurídicos ${ }^{4}$.

\footnotetext{
3 Barcia y Rivera (2015), pp. 24-25. Sobre el principio de intervención mínima del Estado en la familia, puede verse a BARCIA (2011), pp. 26-27.

${ }^{4}$ En este sentido parece pronunciarse TAPIA (2015), p. 236, llegando a sostener que, salvo los de contenido patrimonial como el deber de socorro, "en la actualidad los deberes conyugales personales... quedan entregados a las conciencias de las personas y al modelo de pareja que libremente decidan
} 
$\left.3^{\circ}\right)$ No cabe el cumplimiento forzado de dichos deberes, de modo que tampoco debe proceder la indemnización por su incumplimiento ${ }^{5}$.

$\left.4^{\circ}\right)$ Si se otorgara indemnización de perjuicios por incumplimiento de deberes conyugales se desnaturalizaría su carácter personalísimo y se daría lugar a una especie de monetarización o patrimonialización de dichos deberes. Sería como ponerle precio en dinero a la fidelidad, la ayuda mutua, el respeto y protección recíprocos, etc. ${ }^{6}$.

A todo lo anterior suelen añadirse argumentos prácticos o de conveniencia. Se habla así de lo nocivo que sería que se ventilen judicialmente detalles escabrosos relativos a la vida sentimental de los cónyuges, lo que afectaría a los hijos y a la misma estabilidad de la familia ${ }^{7}$; de que se incrementaría la litigiosidad por las rupturas conyugales, congestionando más aún a los tribunales de familia ${ }^{8}$, y de que incluso podría constituir un desincentivo para contraer nupcias, ya que los candidatos al matrimonio tendrían que pensarlo

otorgarse... Los afectos y el sexo son cuestiones que escapan -afortunadamente- al dominio de la ley civil en una sociedad respetuosa de la autonomía y de la diversidad, y quedan entregados a las afinidades, preferencias y convicciones de las personas". En esta concepción no habría propiamente deberes jurídicos en el matrimonio y ello dependería de la libre voluntad de configuración de la relación matrimonial por los cónyuges. Sin embargo, párrafos más abajo parece contradecirse porque se siente en el deber de aclarar que el hecho de que los deberes conyugales sean "de contenido eminentemente ético o moral" no significa que estén "desprovistos de todo efecto jurídico" ni que no tengan "consecuencias jurídicas específicamente descritas en el derecho de las familias [sic]", hasta llegar a asentar que "desde el mismo momento en que se encuentran descritos en la ley, son deberes de naturaleza jurídica", solo que por su contenido ético no podrían los cónyuges ser obligados a cumplirlos forzadamente o a indemnizar perjuicios por su incumplimiento (p. 237).

${ }^{5}$ Así, TAPIA (2015), p. 244, para quien la inexistencia de la posibilidad de coacción demostraría que no hay un interés jurídicamente protegido, que pueda ser lesionado para implicar indemnización civil. En similar sentido, BARCIA y RIVERA (2015), pp. 22-23, señalan que la responsabilidad civil no debiera proceder por cuanto los deberes matrimoniales no serían "ejecutables".

${ }^{6}$ El autor brasileño De Albuquerque (2015), p. 264, grafica esta postura de un modo ilustrativo: "A priori, surge una aparente disociación entre la idea de familia y la de responsabilidad civil, visto que en cuanto ésta se basa en la consideración de las obligaciones civiles, aquella se presenta como el locus de la afectividad y la plena realización de los individuos que participan en ella. En ese sentido, permitir la entrada de la responsabilidad civil en las relaciones de familia implicaría, como una especie extraña y maléfica de Midas, transformar en dinero lo que es intrínseca y esencialmente afecto".

7 Así, Ramos (2007), p. 117, declara no ser partidario de las demandas de responsabilidad civil entre cónyuges porque es necesario poner término a los problemas de la pareja y, además, porque "estos juicios pueden conducir a situaciones escandalosas, en que se discutan aspectos íntimos de la pareja que no parece sano ventilar públicamente y que pueden producir daños no sólo a los cónyuges, sino a todo el núcleo familiar".

${ }^{8}$ BARCIA y Rivera (2015), pp. 24-25, hablan de una "sobrejudicialización" de los conflictos familiares. 
dos veces antes de acceder a un estatuto con deberes cuyo incumplimiento puede ser sancionado con fuertes indemnizaciones ${ }^{9}$.

Hemos de señalar que, en nuestra opinión, no son correctos los argumentos teórico-conceptuales, mientras que los de tipo práctico pueden enfrentarse sin necesidad de crear una especie de "círculo de impunidad" por ilícitos familiares que causan daño.

Contra los argumentos téorico-conceptuales, puede aducirse:

$1^{\circ}$ ) El hecho de que la infracción del deber de fidelidad tenga sus propias sanciones (art. 132 del Código Civil) no quiere decir que no genere además responsabilidad civil, ya que esta no es una sanción; es sencillamente un instrumento idóneo para permitir al perjudicado obtener la reparación del daño causado ilícitamente. Por ello no se infringe el principio de prohibición de doble incriminación (non bis in idem) cuando concurre una sanción civil propia del Derecho de Familia y la indemnización por los daños causados al violarse deberes conyugales ${ }^{10}$.

$2^{\circ}$ ) El deber de fidelidad no es solo ético, sino también jurídico. Es lo que de alguna manera especifica la naturaleza del vínculo matrimonial ${ }^{11}$. En un noviazgo o "pololeo" no hay deber jurídico de fidelidad, aunque pueda haberlo moral. Tampoco lo hay en las uniones de hecho ni en el reciente acuerdo de unión civil (ley № 20.830, de 2015), para el que intencionalmente fue excluido ${ }^{12}$.

\footnotetext{
9 Se apunta que la indemnización en definitiva "castiga a los que se casan", de modo que se produciría un incentivo a no ingresar al estatuto matrimonial por el mayor costo que ello implicaría: confróntese CON BARCIA Y RIVERA (2015), p. 26.

10 En este sentido, Lepin (2015), pp. 417-418; Bravo (2015), p. 257, y VArGas (2015), pp. 73-74. Comentando la sentencia de Corte Suprema de 13 de junio de 2012, ETCHEBERRY (2012), p. 218, señala que "no basta con que la legislación aplique sanciones especiales, pues éstas persiguen otro fin, que generalmente se traduce en que las familias puedan arreglar su vida futura, pero dichas sanciones en ningún caso reparan los menoscabos demandados".

11 Como señala Rodríguez (2009), pp. 83-84, el hecho de que los deberes familiares tengan un fundamento ético no implica que ellos no hayan sido convertidos en preceptos jurídicos que, aunque de naturaleza personalísima y sin posibilidad de ejecución coactiva, obligan a lo menos inicialmente al infractor a indemnizar los daños que se hubieren producido. En el mismo sentido, Novales (2009), pp. 1945 y ss., para quien estos deberes dan lugar a verdaderos derechos subjetivos si bien de carácter familiar (p. 1956). En Chile, haciendo ver que el carácter ético no priva a estos deberes de su juridicidad, VARGAS (2015), p. 65.

12 González (2014), p. 93, plantea como posibilidad que los deberes de fidelidad y de respeto y protección recíproco entre convivientes civiles se integren al contrato de Acuerdo de Unión Civil en virtud del art. 1546 del Código Civil. Nos parece que ello no es posible, ya que la naturaleza del contrato no permitiría una ampliación de deberes que pasarían a ser de mayor importancia que los que la ley expresamente le atribuye.
} 
$3^{\circ}$ ) Que el deber de fidelidad no pueda exigirse mediante una acción de cumplimiento forzado no implica que su infracción no pueda ser indemnizada. También en el plano patrimonial existen obligaciones que no pueden cumplirse de modo coactivo: obligaciones de hacer cuando la ejecución requiere una calidad personal del deudor u obligaciones de no hacer cuando no puede deshacerse la obra hecha, sin que quepa duda alguna sobre que su incumplimiento sí genera indemnización de los perjuicios causados ${ }^{13}$.

$4^{\circ}$ ) La supuesta monetarización o patrimonialización de deberes personalísimos debe entenderse superada hace casi un siglo cuando se admitió la posibilidad de pedir indemnización por el daño moral por la lesión de derechos de la personalidad o por la pérdida de un ser querido. En estos casos, la indemnización no pretende reparar completamente el daño sufrido, pero sí atenuarlo o compensarlo ${ }^{14}$.

Tampoco son convincentes los argumentos prácticos o de conveniencia. El que se ventilen cuestiones privadas de las personas en los tribunales no es ninguna novedad y ocurre muchas veces: en las procesos de interdicción, en los juicios por violencia intrafamiliar, en los de alimentos o cuidado personal, etc. Más extraviado nos parece el argumento de que la responsabilidad civil por adulterio desincentivaría el matrimonio, porque si en algún caso ello Ilegara a producirse querría decir que no hay voluntad seria de cumplir con la fidelidad, y en ese caso mejor es que la persona no se case. Por otro lado, el que haya un compromiso real de ser fiel sin duda será un plus del estatuto matrimonial por sobre el de la simple unión de hecho o el del acuerdo de unión civil.

Por otra parte, para evitar la litigiosidad excesiva en esta materia bastaría con propiciar una adaptación del régimen de responsabilidad civil al ámbito de confianza y tolerancia de los defectos ajenos que es propio de las relaciones familiares. De esta manera, se pueden modular algunos elementos de la responsabilidad como el factor de imputación, la antijuridicidad o el umbral mínimo de daño resarcible para que se pueda aplicar el instrumento de la

\footnotetext{
${ }^{13}$ Lo mismo sucede con obligaciones derivadas de contratos intuito personae, como el mandato y la sociedad: confróntese con VARGAS (2015), p. 68.

${ }^{14}$ Como apunta De Albuquerque (2015), p. 264, "permitir la entrada de la responsabilidad civil en las relaciones de Derecho de Familia no significa monetarizar la dignidad de los partícipes del entorno familiar, sino disponer de una vía jurídica más para salvaguardar derechos fundamentales, incluso por la vía indemnizatoria. O sea, responsabilizar civilmente al familiar que perturba el núcleo de la familia incumpliendo deberes civiles es perseguir el ideal constitucional de proteger la familia, en cuanto base de la sociedad".
} 
reparación de daños de un modo compatible con las singularidades propias del Derecho de Familia ${ }^{15}$.

Hemos de constatar que una parte importante de los autores nacionales que han tratado el tema en los últimos años se muestran partidarios de esta necesaria complementariedad entre los deberes del matrimonio y las reglas de la responsabilidad civil $^{16}$. La poca jurisprudencia de la que se dispone resulta aún titubeante a nivel de Cortes de Apelaciones ${ }^{17}$ y sin ningún pronunciamiento claro de la Corte Suprema ${ }^{18}$.

15 Por ello se ha sostenido una vía intermedia entre la completa "inmunidad familiar" y la aplicación absoluta e indiscriminada a las relaciones de familia de las reglas de la responsabilidad civil. Se trata de una aplicación modulada o adaptada a las características propias de la familia, como ámbito de afectos, confianza mutua, solidaridad y comprensión. De esta manera, pensamos que en materia de deberes conyugales solo deben considerarse para dar lugar a la reparación civil incumplimientos de carácter grave, de derechos esenciales del matrimonio, cometidos con dolo o culpa grave, y que hayan producido daños que vayan más allá del ámbito de tolerancia propios de la vida en familia: confróntese con CORRAL (2013), p. 344.

${ }^{16}$ Confróntese con Vidal (2004), p. 287; VIDal (2006), p. 254; Pizarro y Vidal (2009), p. 37; Ruz (2011), pp. 437-441; Herane (2011), pp. 105-119; Barrientos (2011), pp. 486-490; Opazo (2012), pp. 589- 605; VAlenzuela (2012), pp. 241-269, y VARGAS (2015), pp. 84-93. Es justo reconocer que el primer autor que se mostró inclinado a asumir esta solución fue SOMARRIVA (1963), p. 135, ya que al examinar el deber de fidelidad da noticia de que la jurisprudencia francesa concede también al cónyuge inocente el derecho a reclamar una indemnización de perjuicios del cónyuge culpable, tras lo cual apunta: "Nuestros tribunales no se han pronunciado sobre el particular, pero bien podrían adoptar igual temperamento, dada la amplitud de la responsabilidad extracontractual y la aceptación unánime que recibe la procedencia de la indemnización del daño moral".

17 Al respecto, puede verse Bravo (2015), pp. 249-265, y Corral (2014), pp. 51-60.

18 No cabe invocar en contra aquellos fallos que han rechazado los recursos de casación en contra de sentencias de apelación que negaban la procedencia de la responsabilidad civil en casos de incumplimiento de deberes matrimoniales, ya que el rechazo ha sido fundado en razones formales, como la inamovilidad de los hechos probados: Strauch con Rosas (2012) Corte Suprema, 6 de marzo de 2012, rol No 778-2011 (casación en el fondo); Prado con Alcalde (2012) Corte Suprema, 13 de junio de 2012, rol № 263-2010 (casación en el fondo); o, además, la improcedencia de alegaciones subsidiarias: Ridell con Albornoz (2012) Corte Suprema, 28 de septiembre de 2012, rol № 6200-10 (casación en la forma y en el fondo). En cambio, una sentencia más reciente (30 de diciembre de 2014, rol № 10622-2014), si bien también rechaza el recurso de casación por razones formales, como obiter dictum indica:"Que amén de las deficiencias del recurso, no se aprecia razón jurídica alguna que permita excluir la aplicación de los artículos 2314 y 2329 del Código Civil, por cuanto la obligación de indemnizar que el fallo impone al demandado no se basa en el mero incumplimiento de los deberes que el matrimonio impone a los cónyuges, sino en la configuración de todos y cada uno de los elementos de la responsabilidad extracontractual, cuales son: una conducta antijurídica, cometida por un sujeto capaz, la culpa del autor, la existencia del daño y el nexo o relación de causalidad entre dicho obrar y el daño provocado...": Pinto con Rojas (2014) Corte Suprema, 30 de diciembre de 2014, rol № 10622-2014, cons. 6º Igualmente, en otro caso en que las sentencias de instancia concedieron indemnización por responsabilidad extracontractual derivada de actos de 
Aclarada la compatibilidad entre Derecho de Familia y régimen jurídico de reparación de daños civiles, resulta conveniente detenerse brevemente en la relación entre este último y la procedencia de las regulaciones de la ruptura del matrimonio.

\section{Responsabilidad civil y divorcio}

Otra de las confusiones que suelen enturbiar esta controversia es la que mezcla dos instituciones que son independientes: la responsabilidad civil por incumplimiento de deberes conyugales, que se propone simplemente reparar el daño injusto, y el divorcio como proceso dirigido a regular una ruptura matrimonial ${ }^{19}$.

Cuando se trata de indemnizar el daño producido por el incumplimiento del deber de fidelidad matrimonial no se requiere ni que se haya promovido el divorcio por la causal relativa al incumplimiento de ese deber, ni que se haya probado la infidelidad en el proceso de divorcio ni tampoco que así se haya declarado en sentencia que lo decrete.

Bien podría ser que el cónyuge víctima solo reclame indemnización de perjuicios y prefiera mantener el vínculo matrimonial, para lo cual, como veremos, se ceñirá a las reglas generales de los procesos de responsabilidad civil $^{20}$.

Por otro lado, para que proceda la causal de divorcio no es necesario que el incumplimiento de deberes matrimoniales haya producido daño o perjuicio moral en el cónyuge inocente. Tampoco se exige que se pruebe daño o perjuicio, basta la prueba del incumplimiento marital con las exigencias señaladas por la Ley de Matrimonio Civil.

A su vez, tratándose de responsabilidad civil será suficiente que la infidelidad haya causado perjuicios al cónyuge afectado y no se necesitará que se acrediten las requisitos que se prevén para el divorcio por falta imputable, esto es, que se trate de una transgresión grave y reiterada de dicho deber

violencia intrafamiliar del marido contra la mujer, la Corte Suprema rechazó la casación en el fondo interpuesta, aunque por inamovilidad de los hechos: confróntese con M.R.J.P. con C.O.A.J. (2015) Corte Suprema, 12 de enero de 2015, rol № 25648-2014 (casación en el fondo).

19 Diversa es la situación cuando se discute la reparación del daño del divorcio en sí mismo y no el producido por el incumplimiento de los deberes conyugales: confróntese con VARGAS (2015), p. 59.

20 Una cuestión distinta es la influencia que podría tener una sentencia previa de divorcio, en la cual se ha constatado el incumplimiento del deber de fidelidad, en el proceso civil en que se demande la indemnización de los daños sufridos por el cónyuge inocente. Véase infra sección IV. 
conyugal y que ella torne intolerable la vida en común (art. 54 de la ley $\mathrm{N}^{0}$ 19.947, de 2004) ${ }^{21}$.

La cuestión queda más clara en aquellos ordenamientos jurídicos que han suprimido el divorcio por culpa para mantener una causal única y objetiva. Esta supresión de la influencia de la infracción de los deberes conyugales en la suerte del vínculo matrimonial no implica que no proceda responsabilidad civil si dicha infracción ha provocado daño. Por ejemplo, las causales de divorcio por culpa (subjetivas) han sido suprimidas por el reciente Código Civil y Comercial de Argentina (2015), pero la doctrina no duda en afirmar que ello no es óbice para que se pueda seguir afirmando la posibilidad de responsabilidad civil entre los cónyuges, cuando uno de ellos ha causado al otro daños injustos ${ }^{22}$.

Esta independencia entre responsabilidad civil y divorcio debe aplicarse igualmente a la separación judicial regulada en los arts. 26 y siguientes de la ley $\mathrm{N}^{0} 19.947$, de 2004. Por ello, no cabría aplicar a un juicio de indemnización de perjuicios por incumplimiento del deber de fidelidad la norma del inciso segundo de dicho art. 26, que dispone: "No podrá invocarse el adulterio cuando exista previa separación de hecho consentida por ambos cónyuges". La inhabilidad para alegar el adulterio se refiere solo al proceso de separación judicial y no puede ser extendida a otros ámbitos. Todo lo cual se entenderá sin perjuicio de las facultades del juez que conozca del proceso de responsabilidad civil para considerar la separación de hecho consentida al momento de verificar si el adulterio ha producido o no daño al cónyuge que demanda la indemnización.

Finalmente, hemos de señalar que no se trata en esta sede sobre la indemnización de los perjuicios ocasionados por el divorcio o por la separación judicial, que es otra materia que suele ser confundida con la reponsabilidad

21 En contra, VARGAS (2015), p. 87, para quien exigir gravedad o reiteración resulta necesario para evitar la proliferación de demandas de responsabilidad civil por simples molestias o daños insignificantes. Por nuestra parte, pensamos que ello debe dejarse a la apreciación del juez, quien deberá evaluar la resarcibilidad del perjuicio, lo que no necesariamente dependerá de la gravedad o la reiteración del incumplimiento marital.

22 EmIL (2016), pp. 15 y ss. El autor señala que el divorcio no es la causal del resarcimiento, "pero sí los hechos o motivos que llevaron al divorcio, o en su caso a la ruptura convivencial, cuando tienen una expansión y gravedad, fuerza dañosa punzante en el prestigio, en las esencias comunes espirituales del otro cónyuge, que de por sí, al margen de la separación conyugal y su disolución, entrañen un verdadero daño extrapatrimonial, debiendo en estos casos ser compensado con carácter autónomo" (p. 17). Por su parte, Kemelmajer (2015), p. 219, hace ver que su opinión contraria a la procedencia de daños por infidelidad conyugal se fundamenta, no en la eliminación del divorcio causado, sino en que el nuevo art. 431 del Código Civil y Comercial califica como "moral" al deber de fidelidad matrimonial. 
civil por incumplimiento de deberes conyugales ${ }^{23}$. Por nuestra parte, estimamos que no cabe hablar de responsabilidad civil por tener que padecer un divorcio o una separación demandada unilateralmente desde que la ley ha facultado a una de las partes para actuar así, de modo que fallaría el elemento de antijuridicidad que, pensamos, es indispensable para que opere la responsabilidad civil $^{24}$.

Con estas consideraciones previas, hemos de concordar con todos los autores que, queriendo negar la procedencia de la responsabilidad civil en el matrimonio, afirman que no puede admitirse una acción de responsabilidad civil por el solo incumplimiento de un deber conyugal, específicamente por el solo hecho de haber adulterado o infringido el deber de fidelidad matrimonial. Tienen toda la razón, el problema es que nadie ha sostenido que la responsabilidad civil pueda surgir del mero incumplimiento de una obligación o deber contractual o legal. Para que se genere la obligación de reparar que es constitutiva de esta responsabilidad, deben reunirse todos los requisitos que son necesarios, en general, para la aplicación de las normas propias del régimen indemnizatorio, a saber: conducta voluntaria, ilicitud, imputabilidad, daño y relación causal.

No nos parece necesario abordar la cuestión de si se trata de responsabilidad contractual o extracontractual ${ }^{25}$, porque la diferencia tiene poca

23 En este sentido, TURner (2013), p. 170.

${ }^{24}$ Solo podrían considerarse los daños producidos por un ejercicio abusivo de la acción de divorcio, pero para ello deberían considerarse los requisitos más estrictos que se exigen para admitir la responsabilidad civil por la interposición de mala fe de acciones judiciales. Sobre este tema puede verse a VARAS (2011), pp. 115 y ss.

25 La literatura extranjera se suele pronunciar por la aplicación del estatuto extracontractual, haciendo ver que se trata de la infracción de deberes legales. En contra, VARGAS (2009), pp. 234-240; y para la legislación chilena: VARGAS (2015), pp. 84-87, quien, al entender que el régimen de la responsabilidad contractual se aplica siempre que el daño se causa por un incumplimiento de una obligación previa cualquiera sea su fuente, estima que debiera aplicarse el estatuto de responsabilidad contractual (que él prefiere Ilamar "obligacional"). Para otros autores nacionales el estatuto adecuado es el de la responsabilidad extracontractual por tratarse de deberes legales: Bravo (2015), p. 260. Considerando ambos sistemas insatisfactorios, a veces se aboga por la construcción de un tertius genus para los daños familiares: así, De Albuquerque (2015), pp. 269-270.

En el caso fallado por la Corte Suprema con fecha 28 de septiembre de 2012, la cónyuge demandante invocó la responsabilidad extracontractual y ante el rechazo de su demanda por los tribunales de instancia por estimarse que en todo caso lo que habría sería una responsabilidad contractual, recurrió de casación en el fondo. No obstante, el máximo tribunal rechazó el recurso por contener alegaciones subsidiarias: Ridell con Albornoz (2012) Corte Suprema, 28 de septiembre de 2012, rol № 6200-10 (casación en la forma y en el fondo). 
relevancia práctica en estas materias ${ }^{26} y$, además, porque si se entiende que pueden concurrir ambas responsabilidades, existe la posibilidad de la opción ${ }^{27}$, $\mathrm{o}$ al menos el planteamiento de una acción en subsidio de la otra si se estima que no procede la opción y que debe primar el contrato (art. 17 CPC).

\section{Elementos de la responsabilidad civil aplicados a la infidelidad conyugal}

\section{Conducta voluntaria}

Para que pueda hablarse de responsabilidad civil debemos estar en presencia de una conducta humana, ya sea activa u omisiva, que haya sido desarrollada voluntaria y libremente.

Las conductas que pueden llegar a configurar una infracción al deber de fidelidad matrimonial son todas positivas, ya que no parece concebible que se pueda ser infiel por una actuación negativa o un mero no hacer.

Un mero no hacer en cuanto a las expresiones del afecto marital o la renuencia a mantener relaciones sexuales de uno de los cónyuges hacia el otro no pueden configurar una infidelidad en el sentido propio que resguarda la exclusividad afectiva y sexual del vínculo matrimonial. Por cierto, ese tipo de conductas omisivas podrá constituir infracción de otros deberes conyugales, como el de cohabitación o ayuda mutua.

Otra característica de la conducta que puede generar responsabilidad civil por incumplimiento del deber de fidelidad consiste en que para concretarse necesita la colaboración de una tercera persona hacia la cual se dirigen las acciones sentimentales o de connotación sexual que se deben de forma exclusiva al otro cónyuge ${ }^{28}$. Esta tercera persona puede ser también casada con otro sujeto diverso, de modo que pueden verificarse dos conductas violatorias de la fidelidad (contra distintos cónyuges) al mismo tiempo.

\footnotetext{
${ }^{26}$ Como es sabido, la jurisprudencia actual de la Corte Suprema admite la indemnización del daño moral en la responsabilidad contractual, especialmente cuando el contrato protege intereses no patrimoniales, como sucede con el matrimonio. Tampoco se aprecian diferencias relevantes en lo referido a la ilicitud, el nexo causal y la mora: confróntese con González (2014), p. 78.

27 Pensamos que si se trata de infracciones a los deberes conyugales que no serían ilícitas de no haber matrimonio entre el autor y la víctima, debería aplicarse el estatuto del incumplimiento contractual, pero es cierto que esos deberes son también legales, y para la mayoría de la doctrina actual, el incumplimiento de obligaciones legales da lugar a la responsabilidad extracontractual, con lo cual se daría un concurso de responsabilidades que debería resolverse dando la opción a la víctima entre uno u otro régimen: confróntese con CORRAL (2013), pp. 32 y ss. y p. 345.

28 De hecho, la palabra "adulterio" (adulterium) viene de las expresiones latinas "ad" (cerca de) y "alterum" (otro).
} 


\section{Ilicitud}

La antijuridicidad o ilicitud se configura por la infracción o incumplimiento del deber conyugal de guardarse $\mathrm{fe}^{29}$. La forma más neta de violación de la fidelidad recibe desde antiguo el nombre de adulterio y que consiste clásicamente en la realización de la cópula sexual entre un varón casado y una mujer que no es su cónyuge o entre una mujer casada con varón que no es su marido. Así lo define el art. 132 del Código Civil: "Cometen adulterio la mujer casada que yace con varón que no sea su marido y el varón casado que yace con mujer que no sea su cónyuge".

El mismo artículo dispone que el adulterio constituye "una grave infracción al deber de fidelidad que impone el matrimonio" (art. 132 inc. $1^{\circ}$ ). Con lo cual se indica, implícitamente, que el adulterio tal como está definido legalmente es solo una de las posibles infracciones graves al deber de fidelidad, de modo que pueden haber otras de igual o menor gravedad ${ }^{30}$.

De este modo, contactos o interacciones corporales de carácter sexual distintos de la cópula podrán ser considerados conductas que contravienen el deber de fidelidad. Por ello, lo serán también las conductas sexuales entre personas del mismo sexo ${ }^{31}$.

Pero es más, la fidelidad no puede entenderse circunscrita solo al elemento sexual (superada la concepción de la fidelidad como ius in corpus). La comunidad de vida que implica el matrimonio no solo es de carácter físico, sino también emocional o sentimental. Excluye no solo las relaciones sexuales con un tercero, sino todos los actos que son propios de una relación amorosa o romántica, aunque no se llegue a la consumación por la cópula u otros comportamientos sexuales.

A todo lo anterior deben añadirse, merced a los avances de la tecnonología, las infidelidades virtuales, que se cometen utilizando las nuevas formas de comunicación a distancia o las llamadas redes sociales.

\footnotetext{
${ }^{29}$ Para la distinción entre deberes y obligaciones en el matrimonio, puede verse a GonzÁlez (2014), pp. 69-76.

30 BarRIENTOS (2011), p. 501, señala a este respecto que se supera la concepción tradicional de la obligación de guardarse fe "como reducida a la simple prohibición de mantener relaciones sexuales con terceros, es decir, circunscrita a la mera exclusión del adulterio, como ligeramente había solido entender la doctrina chilena".

${ }^{31}$ El que el art. 54 de la ley No 19.947, de 2004, enumere la "conducta homosexual" como una causal de divorcio diversa de la transgresión del deber de fidelidad no puede llevar a excluir del campo de las violaciones del deber de fidelidad los contactos sexuales entre personas del mismo sexo. La intención del legislador fue clarificar la procedencia del divorcio en caso de relaciones homosexuales para que no se interpretara que ellas no cabían en el concepto tradicional de infidelidad.
} 
No compartimos, con todo, la opinión que amplía incluso más allá de la exclusividad sentimental o amorosa el deber de fidelidad y de guardarse fe y que llega a abarcar todo comportamiento que venga exigido a los cónyuges por la comunidad de vida que implica el matrimonio. Cualquier deslealtad o acto de descrédito del otro cónyuge o incluso la falta de prestación del Ilamado "débito conyugal" quedarían calificadas como incumplimientos del deber de fidelidad ${ }^{32}$. Nos parece que esta lectura omniabarcante no puede ser aceptada, ya que va contra lo que es el sentido natural y obvio y el uso general de la palabra "fidelidad" en el contexto matrimonial. Además, esa extensión del deber de fidelidad volvería inútiles por superfluos los demás deberes que el Código Civil menciona como emanados del consorcio conyugal: deber de cohabitación, socorro, ayuda mutua, respeto y protección recíprocos (arts. 131,133 y 134). Concluimos, pues, que debe tratarse de una infidelidad sexual o a lo menos sentimental ${ }^{33}$.

Para pedir la indemnización de los perjuicios bastará que se trate de una infidelidad de cierta gravedad, pero no es necesario que la transgresión del deber de fidelidad sea "reiterada", lo que sí se exige para dar lugar al divorcio por falta imputable, según el art. $54 \mathrm{~N}^{\circ} 1$ de la ley $\mathrm{N}^{0} 19.947$, de $2004^{34}$. Insistimos en que resulta necesario independizar ambas consecuencias de la infidelidad: una es la de posibilitar la separación judicial (art. 26 de la ley $\mathrm{N}^{\circ}$ 19.947) o la terminación del matrimonio por divorcio (art. 54 de la ley $\left.N^{\circ} 19.947\right)$ y otra es la obligación de reparar los perjuicios causados al cónyuge víctima.

\section{Imputabilidad}

Parece claro que, al no haber norma especial, a los daños causados por la infidelidad conyugal se aplicará la responsabilidad por dolo o culpa. Pensamos, sin embargo, que en materia de familia debe exigirse algo más

\footnotetext{
32 Así, Barrientos (2011), pp. 500-509, para el cual el deber de fidelidad tendría una dimensión negativa y una dimensión positiva. En esta última, señala que en el plano sexual exige "la entrega corporal mutua y exclusiva que implica la realización de actos sexuales..." (p. 507), mientras que en el campo no sexual puede concretarse, por ejemplo, "en asumir la defensa del cónyuge ausente frente a todo género de ataques o exigir el cumplimiento del derecho a no declarar sobre circunstancias personales del otro" (p. 507).

${ }^{33}$ De Albuquerque (2015), pp. 274-275, entiende que no es posible resolver la cuestión de si procede o no la responsabilidad civil por infidelidad conyugal sin un ejercicio de ponderación de principios e intereses que se contraponen, como la buena fe objetiva y la espontaneidad del afecto, la libertad personal y la solidaridad familiar.

${ }^{34}$ Aunque obviamente la gravedad puede venir dada por la reiteración.
} 
que la mera negligencia. Se hace necesario requerir dolo o, al menos, culpa grave $^{35}$.

Ahora, tratándose del adulterio o de otras infracciones al deber de fidelidad, debe afirmarse que no es posible su comisión por culpa o negligencia. Nadie adultera por descuido. Esta especial transgresión de este deber conyugal exige plena intención y, por lo tanto, se trata de comisión dolosa.

Se ha sostenido que no hay dolo en el adulterio porque nadie es infiel con el especial o único propósito de causar daño a su cónyuge ${ }^{36}$. Pero esto significa insistir en la vieja concepción del dolo que exigiría la presencia de un específico animus nocendi. Tal concepción -tremendamente restringidaha sido felizmente superada por la doctrina más moderna de la responsabilidad civil, la que advierte que normalmente quien actúa con dolo no busca el perjuicio de otro, sino el beneficio propio ${ }^{37}$. El art. 44 del Código Civil define el dolo como la intención positiva de inferir injuria a la persona o propiedad de otro, y la palabra "injuria" está tomada en el sentido de algo injusto o contrario a Derecho. Por ello actúa dolosamente todo aquel que tiene conciencia de estar obrando ilícitamente y con conciencia del daño que su actuación causará a otra persona, aunque lo haga directamente para obtener una gratificación personal ${ }^{38}$.

Quien adultera o es infiel a sus promesas matrimoniales sabe que con ello comete una injusticia en contra de su marido o mujer. Que quiera o no

\footnotetext{
35 Seguimos los argumentos que plantea Rodrícuez (2009), pp. 135 y ss., en relación con los accidentes domésticos y basados en el comportamiento más relajado que se da en el ámbito familiar y en la aceptación mutua de las capacidades y defectos de los cónyuges. En contra, por entender que esa exigencia constituiría un "privilegio familiar" y por las dificultades probatorias, se pronuncia LepIN (2015), pp. 430-43. En este mismo sentido, y con razones similares, Bravo (2015), p. 262.

${ }^{36}$ Así, TAPIA (2015), p. 241, se pregunta: “¿cómo un adulterio puede cometerse con dolo?, ¿acaso las personas son adúlteras con el propósito deliberado de generar daño a su cónyuge?".

37 Por todos, puede verse a BARROS (2006), pp. 159-160.

${ }^{38}$ En este sentido, señala Barros (2006), p. 160, que "lo común del dolo, entendido como culpa intencional resulta ser la utilización voluntaria del otro para los propios propósitos. En tal sentido, el concepto civil de dolo no sólo comprende la intención de dañar en sentido estricto, sino en la aceptación voluntaria del ilícito con conciencia de la antijuridicidad de la acción, donde la intención se puede referir tanto a los fines como a los medios. Sólo en forma excepcional lo querido es el perjuicio ajeno, con exclusión de otro interés. Más generalmente, la intención se reduce a aceptar el daño como una consecuencia colateral de la acción. Pero también se extiende a la simple mala fe (que incluye la actuación temeraria contraria a la decencia y a las buenas costumbres) y al fraude (esto es, el engaño por acción u omisión, abusando de la autoridad o de la experiencia o proporcionando a sabiendas información falsa)". Esta descripción puede adaptarse perfectamente a la conducta del cónyuge que mantiene relaciones amorosas con persona distinta de su marido o mujer.
} 
quiera dañarlo o dañarla es irrelevante para los efectos de una responsabilidad civil provocada por una actuación dolosa ${ }^{39}$.

\section{Daño indemnizable}

Los que se oponen a la responsabilidad civil por incumplimiento del deber de fidelidad parece que piensan que la sola transgresión de este ya haría surgir el derecho a ser indemnizado por el ofendido. Esta es una asunción incorrecta que genera muchos malentendidos ${ }^{40}$. La vulneración de un derecho o el incumplimiento de un deber es una conducta antijurídica, pero ello no implica necesariamente que tal comportamiento ilícito haya causado perjuicios indemnizables.

En nuestro caso, si el cónyuge afectado por el adulterio del otro no tiene ningún afecto por él y le tiene sin cuidado lo que haga con su vida sentimental, por ejemplo, porque llevan separados muchos años, es probable que aunque haya una acción antijurídica ella no dé lugar a indemnización, porque no hay daño; y si no hay daño no procede reparación alguna.

Pensamos igualmente que el daño debe tener cierta magnitud superior a la simple molestia o el disgusto. Así, por ejemplo, no parece que proceda que la mujer obtenga indemnización porque tuvo el desagrado de presenciar cómo su marido le decía un piropo a su secretaria, ni el marido podrá demandar a la mujer por haber enviado una tarjeta de saludos con cierta insinuación amorosa a un compañero de trabajo.

Pero tampoco hay que extremar las cosas y sostener que solo puede indemnizarse el adulterio cuando produzca daños diversos al dolor y a la lesión de la dignidad o la integridad psíquica del cónyuge agraviado. Por ejemplo, si por el adulterio del marido este contrae una enfermedad sexual que luego contagia a su mujer ${ }^{41} \mathrm{O}$ si la mujer comete adulterio y concibe un hijo por obra

\footnotetext{
${ }^{39}$ OtÁrola (2013), p. 133, aunque habla de culpa grave, en realidad parece referirse a supuestos de dolo, ya que habla de que lo relevante es que se exija al autor del daño "cierta previsibilidad, aun cuando no lo hubiese imaginado como posible". En un caso en que la mujer producto de una relación extramarital tuvo una hija que le fue atribuida falsamente al marido, ETCHEBERRY (2012), p. 217, sostiene que "ésta ha sido una conducta dolosa por parte de la cónyuge, no sólo en cuanto al adulterio sino en el ocultamiento de la verdadera paternidad de la menor" (énfasis añadido).

${ }^{40}$ Como señala Sambrizzı (2001), pp. 145-146, la responsabilidad se deriva de la violación de los deberes matrimoniales, "debiendo no obstante tenerse presente que la sola violación de esos deberes no lleva aparejada una responsabilidad resarcitoria, sino en tanto y cuanto produzca daños ya sea materiales o morales".

${ }^{41}$ En un caso resuelto por la Corte de Talca la mujer demandaba indemnización de perjuicios por cuanto su marido le habría transmitido el virus del papiloma humano, después de contraerlo él mismo
} 
de un tercero, pero engaña al marido y le hace pensar durante años que es hijo suyo ${ }^{42}$. En estos casos, por cierto, procederá la indemnización civil, pero no parece que estemos reparando daños producidos por el adulterio, sino más bien por la lesión a la salud o por la ocultación maliciosa o negligente de la verdadera paternidad ${ }^{43}$.

Bastaría, en cambio, comprobar que se ha sufrido daño moral, en la versión tradicional de "menoscabo de un bien no patrimonial que irroga una lesión a un interés moral por una [persona] que se obligaba a respetarlo" ${ }^{44}$. Lo anterior se verá incrementado si con motivo de la confianza herida se desarrolla algún tipo de trastorno psíquico, como una depresión o un colapso nervioso.

en sus relaciones extramaritales: Abarca con González (2012) Corte de Apelaciones de Talca, 31 de agosto de 2012, rol № 133-2012 (apelación).

${ }^{42}$ Como sucede en la jurisprudencia española en virtud de varias sentencias de Audiencias Provinciales. Puede verse un comentario a esta jurisprudencia en De Verda y BeAmonte y Chaparro Matamoros (2015), pp. 132-137. En nuestro país se dio un caso de esta especie en que el marido reclamaba indemnización de perjuicios por el adulterio de su mujer con un tercero, producto del cual la hija que le fue atribuida por la presunción de paternidad resultó ser hija biológica del amante de su mujer, de lo cual se enteró cuando se produjo la separación de hecho del matrimonio. La Corte de Apelaciones de Santiago confirmó la sentencia de primera instancia que denegó la demanda por entender que el adulterio tenía sus propias y especiales sanciones y no podía constituir un delito o cuasidelito civil. Nada se dijo sobre el ocultamiento doloso de la paternidad. La Corte Suprema rechazó el recurso de casación por considerar que se estaban impugnando los hechos ya establecidos sin que se hubieran denunciado infracciones a las leyes reguladoras de la prueba: confróntese con Prado con Alcalde (2012) Corte Suprema, 13 de junio de 2012, rol № 263-2010 (casación en el fondo), cons. $4^{\circ}$ a $7^{\circ}$. Por ello, pensamos que el comentario crítico de EtcheberRy (2012), pp. 215218, no acierta al atribuir a la Corte Suprema los argumentos en contra de la responsabilidad civil por infidelidad que la sentencia de casación solo reproduce como consideraciones efectuadas por "los jueces de grado" (cons. $3^{\circ}$ ) y sin pronunciarse sobre su mérito.

${ }^{43}$ González (2014), p. 90, sostiene que en estos casos el daño causado por infidelidad, de alguna forma, es subsumido en el daño originado por la atribución dolosa de paternidad, "por lo que no cabría separarlo como partida indemnizatoria autónoma". No vemos por qué el daño causado por el incumplimiento del deber de fidelidad tenga que ser subsumido en el de atribución falsa de paternidad. Lo que corresponde es que se reparen todos los perjuicios causados: los de la infidelidad, si los hubo, y además los de la atribución maliciosa de una paternidad falsa. Ya que bien podría haber habido adulterio, pero sin que la mujer procediera a ocultar la verdadera filiación del hijo que da a luz.

44 Domínguez (2000), p. 84. La Corte Suprema en fallo reciente, después de citar esta definición, indica: "En este sentido, el daño moral consiste, equivale y tiene su fundamento en el sufrimiento, dolor o molestia que el hecho ilícito ocasiona en la sensibilidad física o en los sentimientos o afectos de una persona": confróntese con Ravelo con Express de Santiago Uno S.A. (2015) Corte Suprema, 26 de agosto de 2015, rol № 2599-2015 (casación sentencia de reemplazo), cons. $4^{\circ}$. 
En todo caso, insistimos que debe tratarse de un dolor profundo, serio y duradero que merezca ser compensado por una indemnización pecuniaria ${ }^{45}$. Igualmente, habrá que insistir en que no cabe presumirlo de la sola infracción del deber de fidelidad y que el cónyuge demandante debe probarlo ${ }^{46}$.

\section{Relación causal}

También deberá acreditarse que el daño moral experimentado tiene como causa directa el adulterio o la infidelidad del cónyuge, ya que es un elemento de la responsabilidad civil la existencia de un nexo causal entre el hecho ilícito y el daño de la víctima. Los daños indirectos no se indemnizan. Para el establecimiento de la causalidad habrá que ceñirse a las teorías de la adecuación o de la imputabilidad objetiva ${ }^{47}$.

La llamada "culpa de la víctima", recogida en el art. 2330 del Código Civil, no parece aplicable en la práctica en estos casos, porque no se trata aquí, como a veces se cree, de las culpas en el quiebre de la relación matrimonial que pueden ser compartidas con una especie de "empate" de incumplimientos maritales: "el marido fue adúltero pero ello se debió a culpa de la mujer que se preocupaba más de los niños que de su cónyuge" ${ }^{48}$, sino de la exposición imprudente al daño que provoca la infidelidad ${ }^{49}$.

Es difícil concebir que uno de los cónyuges se exponga al daño provocado por la infidelidad del otro. Un supuesto bastante alambicado podría darse si el cónyuge víctima que tiene tendencia a sufrir depresiones deja de tomar sus medicamentos y, por ello cuando se entera del adulterio de su marido o mujer cae en una depresión profunda que lo obliga a hospitalizarse.

\footnotetext{
45 Aunque, como recuerda Ruz (2011), p. 440, la indemnización no puede pretender reparar íntegramente el daño causado, sino solo compensar en parte, ello no se da solo en caso de responsabilidad en relaciones familiares, sino en todos los casos de responsabilidad civil en los que se pide una reparación por equivalente pecuniario de un daño extrapatrimonial.

46 Ruz (2011), p. 440; Valenzuela (2012), p. 255. En el Derecho argentino, después de la entrada en vigencia el nuevo Código Civil y Comercial de 2015, se sostiene que el daño moral generado por hechos producidos en el seno de la familia goza de una presunción iuris tantum: Fumarola (2015), p. 38.

47 GonzÁlezZ (2014), pp. 85-86, piensa que la causalidad es especialmente compleja de establecer con certeza en el caso de daños producidos por incumplimiento del deber de fidelidad, pero es porque la compara con la violación de deberes que revela por sí misma el daño y que se daría igualmente si no hubiera matrimonio entre las partes, como en casos de malos tratos del marido hacia la mujer.

${ }^{48}$ En este sentido, estimando que ello muestra lo inapropiado de aplicar la responsabilidad al incumplimiento de deberes maritales, TAPIA (2015), p. 243.

49 En general, Ruz (2011), p. 441, acepta la limitación de la indemnización por exposición al daño, "desde el momento que la falta de uno de los cónyuges puede llegar a ser atribuida a la actitud del otro".
} 


\section{Legitimación}

El legitimado activo de la acción de responsabilidad será el cónyuge cuya confianza ha sido traicionada por el otro. Habría que pensar si es posible que también puedan demandar víctimas por repercusión, que sufren daño por el daño causado a la víctima directa. En este caso, podrían estar los hijos del cónyuge ofendido.

El legitimado pasivo será el cónyuge que ha cometido la infidelidad. Surge la duda de si podría demandarse también al cómplice en esa infracción, obviamente siempre que fuera consciente de que su copartícipe estaba casado y podía prever el daño que se causaría. Se podría aplicar el art. 2317 del Código Civil y establecer que ambos son coautores del ilícito civil, de modo que responden solidariamente.

El problema mayor es el establecimiento de la antijuridicidad de la conducta del tercero cómplice. El tercero no está obligado por el contrato de matrimonio de su copartícipe, por lo que no infringe el deber de fidelidad. Tampoco pareciera que existe un deber jurídico general de no tener relaciones amorosas o sexuales con personas casadas (como sí podía derivarse de los delitos de adulterio o amancebamiento, hoy derogados). La única forma de concebir la ilicitud de la conducta del tercero cómplice en la infidelidad sería considerarlo un tercero que coopera o incluso induce al deudor a incumplir el contrato, de modo que respondería por lesión del crédito (de fidelidad). Pero esta solución concebida para los contratos patrimoniales no puede ser aplicada de igual manera en contratos como el matrimonio.

En todo caso, para hacer valer la responsabilidad del tercero habría que acreditar una relación de causalidad entre su conducta y el daño sufrido por el perjudicado. La relación de causalidad no podrá establecerse sin un juicio de previsibilidad del daño provocado por el adulterio y esto solo se dará salvo cuando el tercero sea una persona próxima y conocedora no solo del vínculo matrimonial, sino de las circunstancias específicas del cónyuge víctima ${ }^{50}$.

\section{Tribunal competente y juicio}

Luego de la modificación del art. $8^{\circ}$ de la ley $N^{\circ} 19.968$, de 2004, existe consenso en que los tribunales de familia no son competentes para conocer de procesos de responsabilidad civil entre cónyuges, salvo las indemnizaciones patrimoniales que se ventilen en procesos por actos de violencia

50 Sobre esta materia, puede verse el estudio pormenorizado, siguiendo a la doctrina y jurisprudencia española, que realiza VARGAS (2009), pp. 259-296. 
intrafamiliar (art. $8^{\circ} \mathrm{N}^{\circ} 16$ de la ley $\mathrm{N}^{\circ} 19.968$ en relación con el art. 11 de la ley $\mathrm{N}^{\circ} 20.066$, de 2005) $)^{51}$.

Por ello, la demanda de indemnización de perjuicios por incumplimiento del deber de fidelidad deberá interponerse ante los tribunales ordinarios, es decir, ante el juez de letras en lo civil que corresponda al domicilio del demandado (art. 134 COT). No habiendo reglas especiales, se aplicarán las normas del procedimiento ordinario (art. $\left.3^{\circ} \mathrm{CPC}\right)^{52}$. Podrán presentarse medidas prejudiciales o precautorias para asegurar el resultado de la acción de manera de evitar que el demandado oculte o enajene su patrimonio.

No es requisito de la demanda que el matrimonio esté disuelto por divorcio o que haya sido decretada la separación judicial de los cónyuges.

No obstante, si se tramita primero un juicio por divorcio o separación judicial en el que se ha acreditado el incumplimiento grave y reiterado del deber de fidelidad (arts. 26 y $54 \mathrm{~N}^{\circ} 2$ LMC), y así ha quedado asentado en la sentencia firme y ejecutoriada del juez de familia, esta sentencia producirá una cosa juzgada (por prejudicialidad) en el proceso civil de responsabilidad. Se aplicará así la norma del inciso $2^{\circ}$ del art. 427 del Código de Procedimiento Civil y se tendrán por probados los "hechos declarados verdaderos en otro juicio entre las mismas partes" ${ }^{\prime \prime 3}$. De esta manera, estará acreditada la conducta, su antijuridicidad e imputabilidad. No así el daño y la relación de causalidad, elementos que deberán ser probados por el o la cónyuge demandante en el proceso civil.

\section{Excurso final: sobre la tesis de que solo hay responsabilidad por infidelidad cuando se violan derechos fundamentales}

Nos interesa, finalmente, profundizar en la posición que quizás sea hoy la predominante en nuestro medio y que propone que no puede haber

\footnotetext{
${ }^{51}$ Esto después de que la Ley $\mathrm{N}^{\circ} 20.286$, de 2008, modificara el artículo $8^{\circ}$ de la Ley № 19.668 , de 2004, y eliminara una cláusula abierta de competencia establecida en el № 19 de dicha norma que decía que dichos tribunales eran competentes para conocer de "toda otra cuestión personal derivada de las relaciones de familia". Con anterioridad, la cuestión era discutida: SEVERIN (2011b), pp. 343 y ss. y LEPIN (2015), pp. 436-437. La Corte Suprema ha invalidado de oficio alguna sentencia de tribunal de familia que junto con otorgar el divorcio por culpa concedía indemnización de los perjuicios a la demandante: confróntese con Soto con González (2011) Corte Suprema 14 de octubre de 2011, rol № 4392-2011 (casación en la forma de oficio).

52 En este mismo sentido, González (2014), p. 95.

53 Así lo consideró la Corte de La Serena: Pinto con Rojas (2014) Corte de Apelaciones de La Serena 3 de abril de 2014, rol № 507-2003. La casación en el fondo fue rechazada por la Corte Suprema: Pinto con Rojas (2014), Corte Suprema 30 de diciembre de 2014, rol № 10.622-2014, (casación en el fondo).
} 
responsabilidad civil entre cónyuges por el solo incumplimiento de deberes del matrimonio, pero que ella sí procedería cuando ese incumplimiento constituyera además una lesión a un derecho fundamental contemplado en la Constitución o en los tratados internacionales de derechos humanos ratificados por Chile. En este sentido, por ejemplo, se ha sostenido que "la regla general es que la infracción a los deberes del matrimonio no genere por sí sola responsabilidad civil; pero dicha responsabilidad debe proceder en los casos en que concurran causas calificadas de violación de derechos fundamentales, [...], como podría ser la trasgresión[sic] a la dignidad de uno de los esposos o cónyuges" ${ }^{54}$.

Pero ¿qué diferencia en resultados prácticos puede tener esta postura con aquella que defendemos de que el incumplimiento del deber de fidelidad no genera responsabilidad civil por sí solo -lo que es más que obvio y, más aún, necesario en todos los supuestos de responsabilidad civil, ya sea contractual o extracontractual-, sino que ella se produce cuando con ese incumplimiento, el comportamiento infiel, se ha causado un daño al otro cónyuge que supera los límites de la tolerancia debida en el matrimonio? Para fines retóricos, se puede decir que la responsabilidad no surge de la violación del deber de fidelidad, sino de la lesión o violación de un derecho de la persona constitucionalmente protegido, pero la verdad es que por una u otra razón se deberá la reparación del daño causado.

Veamos un ejemplo práctico tomado de la jurisprudencia italiana. La demandante pide resarcimiento de daños no patrimoniales (biológico y existencial) en contra de su marido por incumplimiento del deber de fidelidad, que alega haber sido particularmente humillante para ella dada la notoriedad de la relación adúltera que involucró a otra mujer también casada. En primera y segunda instancia, la demanda es rechazada. Sin embargo, la Corte de Casación, por sentencia de 15 de septiembre de 2011, acoge el recurso de casación presentado por la mujer y declara que la infracción al deber de fidelidad puede dar derecho a la indemnización del daño causado cuando el hecho ilícito haya vulnerado gravemente los derechos inviolables de la persona, como son aquellos objeto de protección constitucional ${ }^{55}$. Hay que tener en cuenta que esta desviación del deber matrimonial hacia el derecho constitucional es la forma en que la Corte de Casación ha estado intentando

\footnotetext{
${ }^{54}$ BarCia y Rivera (2015), p. 45. Mencionan que en España se ha adoptado dicho predicamento y se acepta la responsabilidad civil en caso de infracción a los derechos de igualdad, libertad, honor, intimidad e incluso solidaridad.

55 Casación civil, 15 de septiembre de 2011, № 18853. Tomamos los datos del comentario de Mícuez (2012), pp. 195 y ss.
} 
soslayar la disposición del art. 2059 del Código Civil italiano que restringe el resarcimiento de los daños no patrimoniales a los "casos determinados por las leyes".

Al final, la Corte termina admitiendo en el caso la responsabilidad civil del marido. Pero no alcanzamos a ver qué diferencia puede existir entre exigir prueba de un daño sufrido por la cónyuge ofendida por la infidelidad y requerir, como hace la sentencia, que ese daño sea una lesión a un derecho fundamental o constitucionalmente protegido.

Un comentario a la sentencia publicado en Chile advierte que la doctrina de la sentencia lleva a concluir que en materia de infidelidad se entrará "en el ámbito de la responsabilidad extracontractual, si la conducta del cónyuge, particularmente grave, ha derivado en la lesión de intereses merecedores de tutela, como lo son la salud física y síquica del consorte traicionado, su integridad moral, su dignidad, su honor, su reputación" ${ }^{\prime \prime 6}$. Si esto es correcto, siempre que haya daño significativo por una infidelidad estaremos frente también a una lesión de un derecho fundamental o constitucionalmente protegido: derecho a la integridad psíquica, derecho a la salud, derecho al honor, a la dignidad personal, etc. Esto sucede en todos los supuestos de responsabilidad civil con daños en la persona, pero no por eso necesitamos recurrir a la violación de un derecho constitucional para conseguir el resarcimiento. ¿Alguien podría sostener que la persona atropellada por un camión sólo puede obtener resarcimiento del daño sufrido en la medida en que acredite que ha padecido una lesión al derecho constitucional a la integridad física y síquica? Sería algo superfluo y meramente retórico, porque las normas civiles son más que suficientes para reconocer que se trata de un perjuicio indemnizable.

Se podría contraargumentar diciendo que lo que no se indemniza es el daño meramente moral consistente en el dolor de sentirse engañado por el cónyuge desleal (el Ilamado pretium doloris) ${ }^{57}$. Pero no se entendería la razón de esta exclusión, ya que es claro que ese tipo de daño moral es expresión del derecho constitucional a la integridad síquica, de modo que, según esta postura, debiera resarcirse, aunque no por el mero incumplimiento del deber de fidelidad, sino por haber provocado una lesión seria a dicho derecho fundamental ${ }^{58}$.

\footnotetext{
56 Míguez (2012), p. 200. En el mismo sentido, González (2014), p. 83.

57 Así, al parecer, Mícuez (2012), p. 199, al sostener que el daño relevante "no podrá consistir en el solo sufrimiento psíquico causado por la infidelidad y por la percepción de la ofensa que deriva".

${ }^{58}$ Sobre el respaldo constitucional del daño moral en sus diversas versiones, puede verse a DomínGUEZ (1996), pp. 132-133.
} 
En todo caso, hemos de reiterar, a riesgo de ser calificados de majaderos, que tanto respecto del incumplimiento del deber de fidelidad como de la lesión de un derecho fundamental, no basta que se acredite el hecho ilícito para que se genere responsabilidad civil, sino que es menester que dicho incumplimiento o lesión produzca daños o perjuicios al cónyuge víctima, sea de carácter patrimonial o extrapatrimonial (moral), los que deberán ser debidamente probados en el juicio civil.

\section{Bibliografía CitADA}

Barcia Lehmann, Rodrigo (2011): Fundamentos del Derecho de Familia y de la Infancia (Santiago, Thomson Reuters).

Barcia Lehmann, Rodrigo y Rivera Restrepo, José M. (2015): “¿En qué casos el incumplimiento de deberes del matrimonio genera responsabilidad civil?", en: Revista lus et Praxis ( $\mathrm{N}^{\circ} 21$, vol. 2), pp. 19-60.

Barrientos Grandon, Javier (2011): Derecho de las personas. El derecho matrimonial (Santiago, Thomson Reuters).

Barros Bourie, Enrique (2006): Tratado de responsabilidad extracontractual (Santiago, Editorial Jurídica de Chile).

Bravo Silva, Daniel (2015): "Responsabilidad civil entre cónyuges y ex cónyuges por hechos cometidos durante el matrimonio: Panorama jurisprudencial en Chile, con especial referencia a la sentencia de la Corte de Apelaciones de La Serena de 3 de abril de 2014", en: Vidal, A.; Severin, G. y Mejías, C. (edits.), Estudios de Derecho Civil X, Jornadas Nacionales de Derecho Civil, Valparaíso 2014 (Santiago, Thomson Reuters), pp. 249-265.

Corral Talciani, Hernán (2013): Lecciones de responsabilidad civil extracontractual, 2 ${ }^{a}$ edición (Santiago, Thomson Reuters).

Corral Talciani, Hernán (2014): "La incipiente jurisprudencia chilena sobre daños en la familia", en: Revista de Derecho de Familia (No 4), pp. 51-60.

De AlbuquerQue, Raul Cézar (2015): "A (des)consideração do direito à fidelidade do cônjuge: um contributo à teoria da responsabilidade civil familiar", en: Revista Fórum de Direito Civil (4, 10), pp. 97-140.

De Verda y Beamonte, José Ramón y Chaparro Matamoros, Pedro (2015): "La responsabilidad civil en el ámbito de las relaciones de familia en España", en: LePIN, Cristián y VARGAS, David (edits.), Responsabilidad civil y familia (Santiago, Thomson Reuters), pp. 132-137.

Domínguez Águila, Ramón (1996): "Aspectos de la constitucionalización del Derecho Civil chileno", en: Revista de Derecho y Jurisprudencia ( $N^{\circ}$ 92, vol. 3), pp. 107-137. 
Domínguez Hidalgo, Carmen (2000): El daño moral (Santiago, Editorial Jurídica de Chile), tomo I.

EMILO JaLIL, Julián (2016): “El daño moral derivado de la disolución del matrimonio o de las uniones convivenciales en el nuevo Código Civil y Comercial", en: Revista de Responsabilidad Civil y Seguros (año XVIII, 3), pp. 15-25.

EtCheBERry Court, Leonor (2012): “Responsabilidad civil ante el quebrantamiento del deber de fidelidad entre cónyuges. Corte Suprema 13 de junio de 2012", en: Revista Chilena de Derecho Privado (19, 2012), pp. 215-218.

FumArola, Luis Alejandro (2015): "El resarcimiento del daño moral en el ámbito de las relaciones familiares", en: Revista de Responsabilidad Civil y Seguros (año XVII, 12), pp. 34-42.

González CAZorla, Fabián (2014): “Incumplimiento de deberes conyugales y acciones indemnizatorias: un análisis sobre su procedencia", en: Derecho y Justicia ( $\left.\mathrm{N}^{\circ} 4\right)$, pp. 51-100.

Herane Vives, Francisco (2011): "Reparación por incumplimiento de los deberes matrimoniales", en: Corral, Hernán y otros (coords.), Estudios de Derecho Civil V: Familia y Derecho Sucesorio (Santiago, Abeledo-Perrot), pp. 105-119.

Kemelmajer de Carlucci, Aída (2015): "La eliminación del divorcio contencioso en el proyecto de Código Civil y Comercial de la República Argentina y su incidencia en el Derecho de Daños", en: LepIN, Cristián y VARGaS, David (edits.), Responsabilidad civil y familia (Santiago, Thomson Reuters), pp. 194-221.

Lepin Molina, Cristián (2015): "Responsabilidad en las relaciones de familia", en: LEPIN, Cristián y VARGAS, David (edits.), Responsabilidad civil y familia (Santiago, Thomson Reuters), pp. 397-438.

Míguez Núñez, Rodrigo (2012): "Daño moral por adulterio. Corte Suprema de Casación No 18853/2011", en: Revista Chilena de Derecho Privado (No 19), pp. 195-2012.

Novales Alquézar, María Aranzazu (2009): Las obligaciones personales del matrimonio en el Derecho Comparado (Madrid, Fundación Registral).

Opazo GonzÁlez, Mario (2012): “El principio de la reparación integral del daño y los daños causados por adulterio", en: ElorRIAGA, Fabián (edit.), Estudios de Derecho Civil VII (Santiago, Abeledo-Perrot), pp. 589- 605.

OtÁrola EspinOza, Yasna (2013): "La culpa en materia de derecho matrimonial", en: Domínguez, Carmen y otros (coords.), Estudios de Derecho Civil VIII (Santiago, Thomson Reuters), pp. 125-134. 
Pizarro, Carlos y VIDal, Álvaro (2009): La compensación económica por divorcio o nulidad matrimonial (Santiago, LegalPublishing).

Ramos Pazos, René (2007): Derecho de Familia, 6a edición (Santiago, Editorial Jurídica de Chile).

Rodríguez Guitıán, Alma María (2009): Responsabilidad civil en el Derecho de Familia: especial referencia al ámbito de las relaciones paterno-filiales (Madrid, Thomson Reuters).

Ruz LÁrtiga, Gonzalo (2011): "La reparación integral del daño: ¿mito o realidad?", en: Corral, Hernán et al. (coords.), Estudios de Derecho Civil IV: Responsabilidad extracontractual (Santiago, Abeledo-Perrot), pp. 425-441.

Sambrizzı, Eduardo (2001): Daños en el Derecho de Familia (Buenos Aires, La Ley).

Severin Fuster, Gonzalo (2011a): "Indemnización entre cónyuges por los daños causados con ocasión del divorcio", en: Corral, Hernán et al. (coords.), Estudios de Derecho Civil IV: Responsabilidad extracontractual (Santiago, Abeledo-Perrot), pp. 164-206.

Severin Fuster, Gonzalo (2011b): "Incompetencia del tribunal de familia para conocer las demandas de daño por infracción a las demandas de los deberes conyugales", en: Corral, H. et al. (coords.), Estudios de Derecho Civil V: Familia y Derecho sucesorio (Santiago, Abeledo-Perrot), pp. 343-356.

Somarriva Undurraga, Manuel (1963): Derecho de Familia (Santiago, Editorial Nascimento).

TAPIA RodríGuez, Mauricio (2015): “Aproximación crítica a la indemnización de perjuicios por incumplimiento de deberes conyugales", en: VIDAL, A.; Severin, G. y MejÍAs, C. (edits.), Estudios de Derecho Civil X (Santiago, Thomson Reuters), pp. 233-234 [republicado pero con el título "Contra la indemnización de perjuicios por incumplimiento de deberes conyugales", en Lepin, Cristián y Gómez De LA TORRe, Maricruz (edits.), Estudios de Derecho Familiar I, Santiago, Thomson Reuters, 2016, pp. 163-179.

Turner Saelzer, Susan (2013): "Deberes personales derivados del matrimonio y daños en la jurisprudencia chilena", en: Domínguez, Carmen y otros (coords.), Estudios de Derecho Civil VIII (Santiago, Thomson Reuters), pp. 165-173.

Valenzuela del Valle, Jimena (2012): "Responsabilidad civil por el incumplimiento de obligaciones matrimoniales y por el ejercicio abusivo del divorcio unilateral. Un estudio de su admisibilidad en Chile", en: Revista de Derecho de la Universidad Católica del Norte (19, 1), pp. 241-269. 
VARAS BRAUN, Juan Andrés (2011): "Responsabilidad aquiliana por el ejercicio de acciones judiciales", en: Corral, Hernán et al. (coords.), Estudios de Derecho Civil IV: Responsabilidad extracontractual (Santiago, AbeledoPerrot), pp. 215-228.

Vargas Aravena, David (2009): Daños civiles en el matrimonio (Madrid, La Ley).

Vargas Aravena, David (2015): "Del resarcimiento en Chile de los daños causados en el matrimonio", en: Revista lus et Praxis ( $\mathrm{N}^{\circ} 21$, vol. 1), pp. 57-100.

Vidal Olivares, Álvaro (2004): "La compensación económica en la Ley de Matrimonio Civil. ¿Un nuevo régimen de responsabilidad extracontractual?", en: Revista de Derecho Universidad de Concepción (215-216), pp. 265-297.

Vidal Olivares, Álvaro (2006): “La compensación por menoscabo económico en la Ley de Matrimonio Civil", en: VIDAL, Álvaro (coord.), El nuevo derecho chileno del matrimonio (Ley No 19.947 de 2004) (Santiago, Editorial Jurídica de Chile), pp. 217-287.

\section{JURISPRUDENCIA CITADA}

Soto con González (2011). Corte Suprema, 14 de octubre de 2011, rol № 4392 2011 (casación en la forma de oficio).

Abarca con González (2012). Corte de Apelaciones de Talca, 31 de agosto de 2012, rol № 133-2012 (apelación).

Strauch con Rosas (2012). Corte Suprema, 6 de marzo de 2012, rol № 778 2011 (casación en el fondo).

Prado con Alcalde (2012). Corte Suprema, 13 de junio de 2012, rol № 2632010 (casación en el fondo).

Ridell con Albornoz (2012). Corte Suprema, 28 de septiembre de 2012, rol $\mathrm{N}^{0}$ 6200-10 (casación en la forma y en el fondo).

Pinto con Rojas (2014). Corte de Apelaciones de La Serena, 3 de abril de 2014, rol No 507-2003 (apelación).

Pinto con Rojas (2014). Corte Suprema, 30 de diciembre de 2014, rol $\mathrm{N}^{0}$ 10622-2014 (casación en el fondo).

Ravelo con Express de Santiago Uno S.A. (2015). Corte Suprema, 26 de agosto de 2015, rol № 2599-2015 (casación en la forma y en el fondo).

M.R.J.P. con C.O.A.J. (2015). Corte Suprema, 12 de enero de 2015, rol $N^{\circ}$ 25648-2014 (casación en el fondo). 